\title{
PROCEDURAL MODELLING FOR HBIM OF ITALIAN RAILWAYS IRON BRIDGES
}

\author{
D. Di Donato ${ }^{1}$, R. Morganti ${ }^{1}$, A. Tosone ${ }^{1}$, M. Abita ${ }^{1}$ \\ ${ }^{1}$ University of L’Aquila, Italy - Email: danilo.didonato@univaq.it, renato.morganti@univaq.it, alessandra.tosone@univaq.it, \\ matteo.abita@univaq.it
}

Commission II

KEY WORDS: Tubular truss bridges, Italian railway, Iron and cast iron,VPL, Construction history, HBIM, Algorithm.

\begin{abstract}
:
The development of the railways network in the $19^{\text {th }}$ century represented a significant scenario for the technological advancement of the entire Italian building sector; consequently, it produced a relevant renewal of construction techniques. Icons of this robust infrastructure building program were the railway bridges built over the Po river; their construction represented an arduous technological challenge. Unfortunately, in the years following the proclamation of the Kingdom of Italy the national industry was disorganized and unprepared to face this ambitious challenge; indeed, the first four bridges were built by foreign companies that could guarantee the necessary technological know-how. However, the industrial scenario immediately changed and the last two bridges were designed and built by Italian engineers and steelwork companies. The railway bridges over the River Po are now lost; the changing needs of railway traffic or bombings during the Second World War unavoidably led to their demolition. Their enhancement through $3 \mathrm{~d}$ modelling and virtual representation is fundamental for the rediscovering of the role they played not only in the construction of the national infrastructural system but also in the life of the young state. To this aim, the paper proposes the outcomes of research that explores the potentialities of 3d software with Visual Programming Language (VPL), in order to create modelling tools useful for the disclosure and dissemination of the historical value of this lost heritage.
\end{abstract}

\section{INTRODUCTION}

The research area focusing on the development of Italian railway network was only in part investigated by construction history (Carughi and Guida, 2003; Iori et al., 2015; Nascè, 1982; Zordan, 2006; Zorgno, 1988); however, it represented in the $19^{\text {th }}$ century a privileged scenario for the technological advancement of the entire national building sector; consequently, it produced a significant renewal of construction techniques. This process consisted of a technology transfer based on import techniques for most of the $19^{\text {th }}$ century. However, in the last decades of 1800s, the young Italian metal engineering industry also offered a mature and competitive contribution to the realization of the ambitious infrastructural program. Icons of this technological breakthrough were also the new iron railway bridges. A singular aspect linked to their construction was the extreme variety of technological solutions due to the involvement of technicians and builders from different countries. Yet within this multifaceted framework some structural-construction schemes prevailed on the others; in particular, the tubular truss system represented a leitmotiv in the realisation of the best-known infrastructures, the six iron bridges over the Po (Nascé, 1982).

Today we only keep the memory of these bridges because various reasons led to their progressive replacement.

The goal of the paper is to rediscover them highlighting the role they played not only in the process of innovation and experimentation of construction techniques, but also in the development of the infrastructural system of the young unified state. Therefore, the paper wants to combine the traditional historical research with smart $3 \mathrm{~d}$ modelling tools, in order to show the architectural features of these bridges and the complex system of relationships that their construction introduced in the Po valley landscape.

In the field of Construction and Engineering history the use of $3 \mathrm{~d}$ modelling to rediscover ancient or Modern Movement buildings has only partially explored (Capurso and Giannetti, 2019; Iori et al., 2019).

According to best practices regarding HBIM methodology, the paper aims to show the results of a study addressed to the definition of a VPL (Visual Programming Language) algorithm (Dore et al., 2013; Dore et al., 2019). This tool can be useful to model a large variety of case studies, focusing primarily on railway bridges over the Po.

Unlike the traditional workflow of HBIM operational methodologies, not all the aspects of this experimental area were used (Andriasyan et al., 2020; Brumana et al. 2013; García Valldecabres, 2017; Murphy et al. 2013); in particular, the execution of point cloud surveys was impossible because the bridges were demolished more than a half century ago. Their technological obsolescence for the changing of railway traffic or bombings during the Second World War unavoidably led to their demolition.

Other features of HBIM methodology were strictly followed, such as the definition of special libraries, in order to manage the geometrical features of iron and steel profiles, often produced through handcrafted carpentry (Sztwiertnia et al., 2019). The lack of components standardization didn't allow the use of BIM libraries already available by software; a a consequence specific tools were needed, in order to guarantee an adequate operational flexibility to model the singular features of the old iron and steel components.

These tools can be considered an original contribution in the research field of HBIM. In fact, the related studies mainly focus on the historic architecture built in masonry and traditional building materials (Diara and Rinaudo, 2019; Verdiani et al., 2014); however, few researchers tried to adapt the HBIM approach to iron architecture (Donato, 2017; Pereira et al., 2021; Quin et al., 2021). Some of these studies (Yang et al., 2020) also proposed a VPL modelling of metal constructions using Dynamo in Autodesk Revit. In these cases, the VPL was used to process the point cloud survey and not as a parametric 
tool to model variable configurations of $3 \mathrm{~d}$ modelling depending on input data.

The innovative aspect of the research consists of the definition of an open and free algorithm, expandable and able to make 3d models of a wide range of tubular iron truss bridges (Bianconi and Filicci, 2021) The algorithm is organized in several parts: the first one consists of the input section for the insertion of data and it is arranged into subsections, respectively related to spans (number, width and length), geometry, size of trusses and decks, sections of iron profiles used for iron members.

\section{THE CASE STUDY: THE RAILWAY BRIDGES OVER THE RIVER PO}

The bridges over the River Po were built between 1863 and 1892 and they represented relevant works for the development of typological, technological and building features of the bridges with truss scheme (Figure 1). The specific typology was imported in Italy a few decades after its introduction into construction industry. Indeed, the first truss bridges were built of wood around 1836 in the United States, at the end of a process of gradual stiffening of arch bridges as showed in the Burr type bridges. In particular, the iron lattice called "Town", initially experimented in Great Britain, was later widely used by German engineers who built the largest iron bridges with this structural scheme between 1852 and 1859, such as those located in Offenburg and Dirschau (Iodice, 1985; Nascè, 1982). Starting from 1857, also French engineers began to know its potential renaming it "ponts en treillis" and their experimentations favoured the introduction of this kind of bridge also in Italy. In the peninsula, its import was requested for a specific reason that arose immediately after the Unification of the country: the political unity had to be strengthened by the infrastructural connections in the territory, such as the development of the national railway network. However, the River Po represented a crucial barrier for the railway linking of a great part of the country and its crossing was immediately considered a strategic goal. Unfortunately, the national construction industry wasn't ready to support this ambitious technological challenge and then it was necessary to resort to French technology and building industry, which was responsible for the construction of four of the six bridges built over the River Po in just ten years. After the building of the first bridge in Piacenza on the railway line directed to Milan, the others were located in Mezzana-Corti on the line between Pavia and Voghera - in Pontelagoscuro - on the line between Bologna and Padova - in Borgoforte - on the line between Mantova and Modena. The Piacenza Bridge was designed and built by the Parisian company Parent, Schaken, Caillet; the Mezzana Corti Bridge was built and designed by another company of the French capital, Ernest Gouin and C. with the collaboration of Eng. Pasquale Valsecchi, the director of the works of the Italian Society for Southern Railways; the Pontelagoscuro Bridge was designed by the engineer Gaetano Ratti of the Society of Railways of Northern Italy and it was built by the Moreaux Company; finally, the Borgoforte Bridge was built by the Joret company, also with the collaboration of Eng. Ratti (Bianchi, 1912; Broglio, 1872; Giornale del Genio Civile, 1870; Pozzi, 1915; Ratti, 1874; Ratti, 1876; Ratti, 1879; Valsecchi, 1868). A turning point was represented by the construction of the last two bridges respectively placed in Casalmaggiore and Cremona, both designed by the Civil Engineering Department and built by Società Nazionale delle Officine di Savigliano (SNOS) based near Turin (Beduzzi, 1900; Croci, 1888; Sacheri, 1888; Sacheri 1892). They established the technological goals that the national industry could finally reach.
These bridges could be considered as strategic infrastructures for the functioning of the whole nation and their related historical events are exemplary of the continuous efforts of the state addressed to grow and develop its industry and its infrastructural network also during difficult war phases. For example, the need to strengthen the infrastructural system led in 1931 to replace some of them, as in the case of the old deck of Piacenza Bridge, that was demolished to double the railway line. Also the bombings in 1944 for the "Mallory Major" operation caused important damages to bridges structures, worsening the division between the two states caused by the armistice of 1943 and the Republic of Salò. Only a few strategic railway bridges survived with some damages to the bombings, one of them was the Casalmaggiore Bridge, but they were progressively replaced after the war for a necessary technological adaptation (Caccialanza, 2013).

The historical and technological importance of the iron bridges over the River Po can be rediscovered in this paper through 3D tools based on VPL.

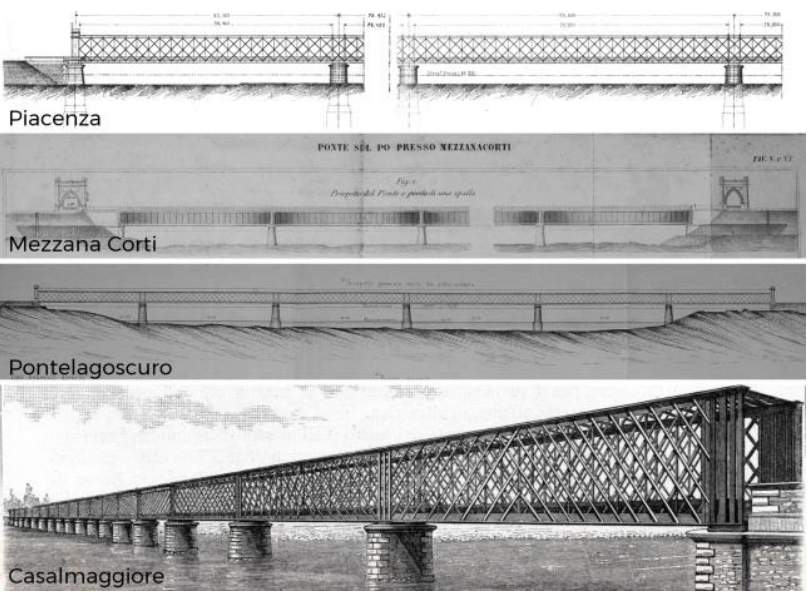

Figure 1. Some railway iron bridges over the River Po.

\section{VPL AND PARAMETRIC MODELLING}

The use of parametric design tools with VPL is a consolidated operational methodology in various areas of virtual representation by now. The dataflow visual programming language was already introduced in the software sector starting from the Seventies and the early Eighties with the application in various research fields (Johnston et al., 2004; Repenning, 2017). The implementation of open source tools such as Grasshopper and Dynamo within proprietary BIM or $3 \mathrm{~d}$ Cad softwares, considerably extended their potential, also in the field of HBIM studies (Brusaporci, 2017; Brusaporci et al., 2018; Brusaporci et al., 2021). Indeed, the VPL is particularly suitable to define routines addressed to the graphic rendering of the morphology of complex geometry such as vaulted decks or decorative components (Oreni, 2013; Previtali et al., 2020). These researches result in reliable and consolidated operational methods which also allow us to imagine wide research and development boundaries. The use of these tools is consistent with HBIM requirements related to the definition of interoperable and open libraries. However, a bottleneck is represented by the problem that, despite the most common VPL tools are open source, they can be used within operating systems of proprietary software and this inconsistency limits their exploitation open to all categories of users.

This essay intends to show how parametric design of the casestudies, only using open source software, could overcome these problems, experimenting at the same time the potential of latest 
tools introduced in the development of some computer graphics software. These tools were chosen according to various aspects such as the possibility of exploiting parametric design methods, the availability of environments dedicated to VPL and the management of complex models, characterized by a large number of components. Therefore, three distinct options were evaluated: the first one consists of the use of SketchUp with a specific plugin, the Open Nodes Editor; the second one consists of the use of Freecad, which allows the parametric design also manageable with the internal spreadsheet and the use of VPL through the activation of external "workbenches" that integrate the software with Dynamo and with Pyflow, albeit in an experimental form; the third one includes the use of Blender which, through some modifiers, is able to manage the parametric design with the integration of special add-ons, such as Sorcar and, above all, Sverchok, which was developed as an alternative to Grasshopper in Blender. However, starting from version 2.82 Blender has recently introduced a native VPL environment, the Geometry Nodes. Even though it is under development, it shows a remarkable potential with its userfriendly approach and the extreme ease of management of complex models. For this reasons the third option was chosen for the modelling, also because the resort to SketchUp would have not allowed relying only on open source softwares and its Open Nodes Editor doesn't guarantee the adequate reliability. Also in the case of Freecad, the use of additional workbenches is not immediate and is partly cumbersome, although the possibility of having modifiers within the software guarantees considerable potential in terms of parametric design. The choice to use in Blender the Geometry Nodes instead of Sverchok is motivated by the opportunity to experiment the internal environments of the software without recurring to specific addons, although this Add-on was developed since more years and characterized by greater potential.

\section{METHODOLOGICAL APPROACH}

The methodology developed for the bridges was organized in a coordinated sequence of 8 phases (Figure 2). The first step consists of the research of historical documentation and includes the analysis of the sources concerning bibliographical and archival research that is necessary to increase the level of knowledge of this singular lost heritage. The outcome of this process is preparatory to the next phase, useful to define the typological characteristics of the truss structures with a tubular section and, in particular, to identify the different components of the structure. The resulting taxonomic classification allows to recognize the system of typological variables and invariants corresponding to each component - the single members - and macro-components - the lateral trusses and decks - defining also the functional parameters for the graphics rendering of the various bridges; this step is essential to proceed with the logical design of the architecture of the VPL algorithm. On the basis of the parameters represented by the systems of variables and invariants, it is possible to select which operational sequences can be shared with all the elements of the different case studies, and which factors must be introduced to restore their original characteristics. For example, an important aspect of the invariant system is the geometric scheme that contributes to the design of the lattice members, both of trusses and decks, that represents the organization outline useful to graft as in a musical score the set of rules that are developed to describe the exceptions characterizing each case-study. These variables correspond to the different number and length of the bridge struts. Other variables are the morphological and size characteristics of the sections of each strut.
For this reason the next step of the methodology consists of the definition of a library for all the possible geometric configurations of the member sections; this abacus is organized into specific objects that describe a series of operations that are suitable for the design of the different profiles, predetermined with respect to the shape but flexible with respect to the size, in order to model in detail the geometrical features of members.

Unlike the previous step, an independent phase is the definition of the operations aimed at the design of the $1 \mathrm{~d}$ model that can be used to carry out structural verifications afterwards, in order to validate the design hypotheses and the comparison between the calculation systems used in the $19^{\text {th }}$ century and the contemporary finite element analysis. The $1 \mathrm{~d}$ model allows at the same time to extend the use of the algorithm to the study of other bridges, such as the one, still in operation, located on the Ticino River, near the town of Oleggio, whose structural features are entirely comparable to that in the Mezzana Corti. The $3 \mathrm{~d}$ model can be easily obtained by assigning the sections available in the library to the members of the $1 \mathrm{~d}$ model. This step represents the last phase of the methodology; it is partially carried out with an automatic form because it requires a further level of input, related to the system of variables defined in the previous steps, useful to introduce not only the size features of each section, but also the precise location of the bridge members.

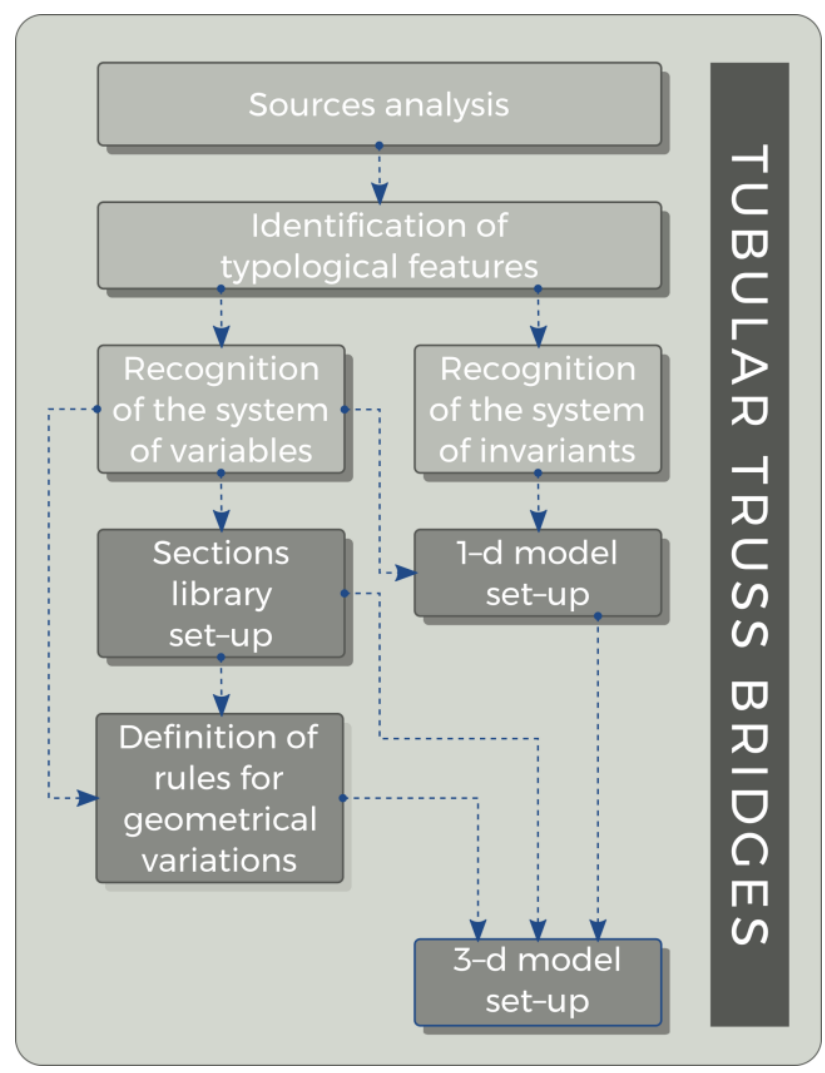

Figure 2. The layout of phases proposed in the methodology.

\section{LIBRARY OF MEMBERS SECTIONS}

In the railway bridges over the River Po the repetition of common aspects can be easily recognized. These are due to precise design choices related to: the size and depth of the watercourse, the progress of the time in building science and the features of iron constructions of the time that spread in Italy in second half of the $19^{\text {th }}$ century, after an occasional and sporadic use in the pre-unification period. These bridges are 
characterised by straight trusses, with tubular section and rectangular profile, made of lattice iron structure and sustained by masonry piers sunk in the riverbed with tubular pneumatic foundations. These recurring aspects represent the system of invariants proposed in the methodological procedure.

The geometric and technological features of trusses are different for the analysed bridges, such as the size of the iron lattices, the use of vertical struts and the iron profiles used for each member. Unlike the invariants, these aspects represent the set of variable parameters. In particular, they concern the following aspects: in the Piacenza Bridge the iron lattice is a large mesh, with vertical struts (battened sections), compressed and stretched diagonal braces respectively made of I-shape profiles and plates; in the Mezzana Corti Bridge a tight mesh, with trellis used for struts and diagonal braces made of plates; in the Pontelagoscuro Bridge a large mesh without struts with compressed and stretched diagonal braces respectively made of compound and U-shape profiles; in the Borgoforte and Casalmaggiore Bridges a medium-length mesh, with vertical posts located inside the lattice girders, with compressed and stretched diagonal braces respectively made of U-shape profiles and plates; in the Cremona Bridge a large mesh built of Tee-shaped profiles. In the bridges located in Piacenza, Mezzana Corti, Pontelagoscuro and Cremona horizontal members consisted of an open section with a $\Pi$ shape, whereas in the other two bridges they are $\mathrm{T}$ shaped sections. Starting from this classification, a summary table was organized (Figure 3). The outcome of this study led to the definition of the section library, according to a consolidated approach in HBIM that allowed the modelling of architectural elements through parametric tools. In this specific case, the arrangement of the libraries included the organization of operational sequences designed to render $2 \mathrm{~d}$ sections.

This approach was used for all types of sections, with the exception of "trellis" and "battened" sections, defined as $3 d$ objects. Each section was defined exploiting the potential guaranteed by the groups of Geometry Node within Blender. Group Nodes are a "collection of nodes that can be combined into a single node while selectively exposing inputs of the embedded nodes". The use of nodes for the section was advantageous to develop a routine, that was able to repeat organized sequences of operations with respect to the input system, locally defined each time. This workflow allows to copy again and again the groups to which assign different values to the input parameters for each of them.

The library was organized in 15 groups, each one useful to the modelling of specific geometric shapes (Figure 6). The possibility to recall other groups with their organization in a hierarchy made it possible to easily model the compound sections, such as those with $\mathrm{C}$-shape or coupled $\Pi$. The correct orientation of the structural components was managed by the rotation of the section that was introduced in the VPL as a control parameter. The modelling and visualization operations of the various bridges were simplified through a trick in their representation: the compound sections made of angles and plates that represented more complex elements, were developed with their assembled shape, namely the whole envelope figure, excluding the design of each single part which would have produced a computational, at the expense of a user-friendly approach.

\section{VPL ALGORITHM IN BLENDER}

The design of the algorithm is necessarily consistent with the workflow in Geometry Nodes (Blender, 2022). Therefore, the library of available nodes inspires the layout of functions sequences both for the model composed of lines (1d elements forming the $1 \mathrm{~d}$ model) and the $3 \mathrm{~d}$ model (Figure 4).

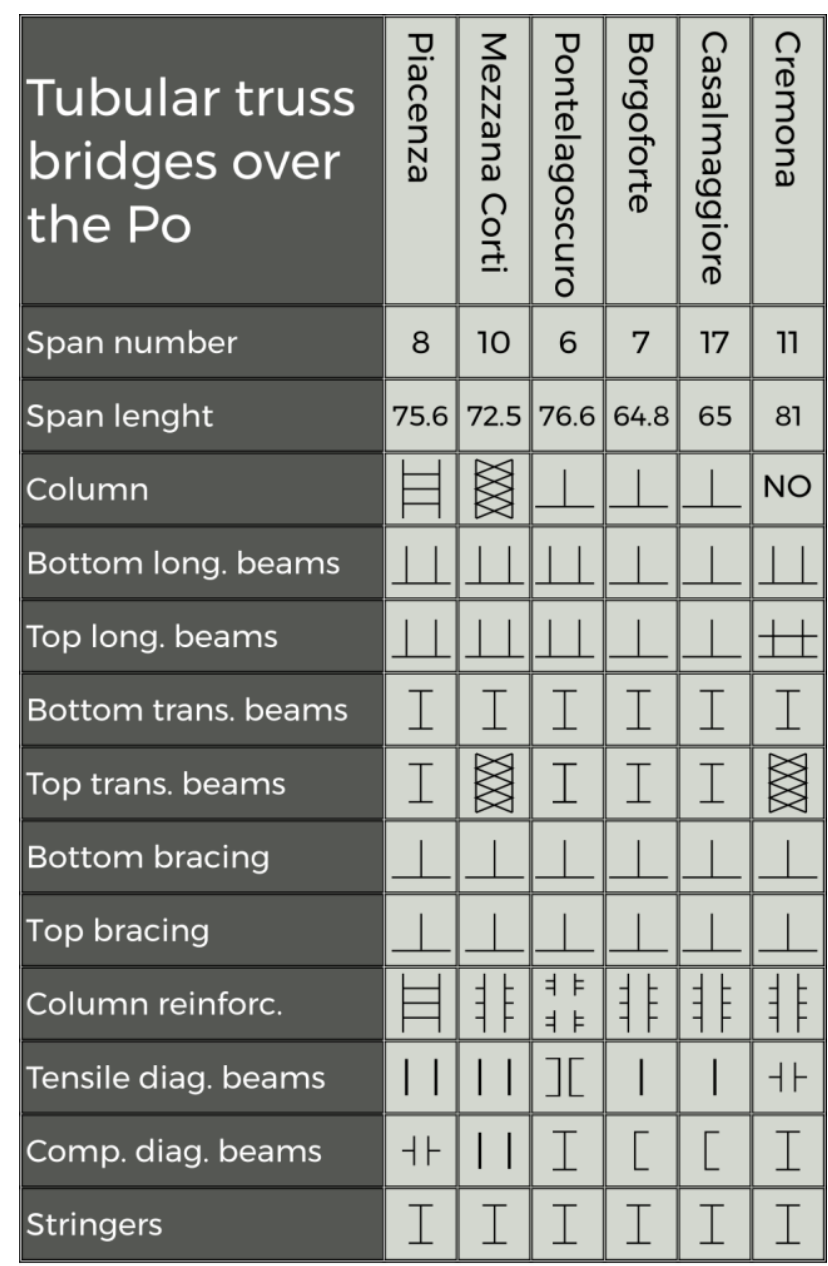

\section{LEGEND}

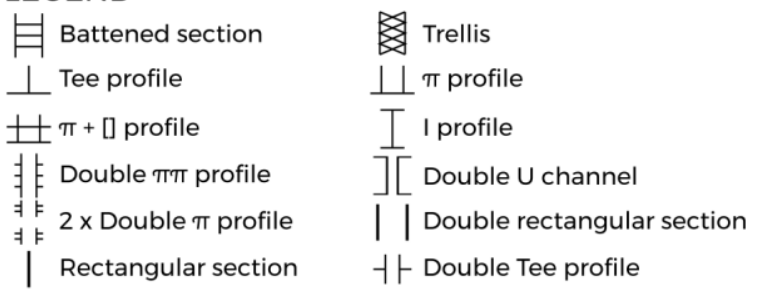

Figure 3. The summary table of typological features of bridges.

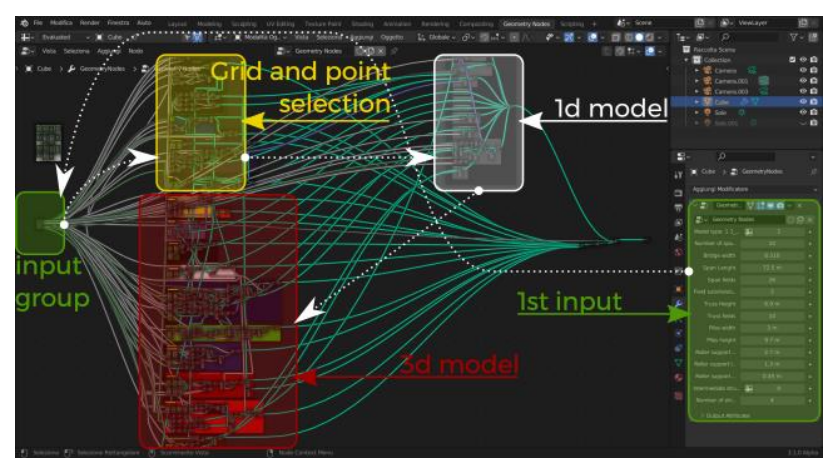

Figure 4. The VPL algorithm in the Blender's Nodes Geometry.

Even though the node type is rather limited in number, their combined use through several copies leads to a particularly complex tree graph for the algorithm. In particular, some node types such as Mesh Line and Mesh Grid are fundamental for its development; the first "generates vertices in a line and connects 
them with edges"; the second "generates a planar mesh on the XY plane". These nodes are functional to the use of arrays within the Geometry Nodes; in the case of grids, each matrix has a domain $n * m$, where $m$ is the number of rows and $n$ that of columns corresponding to a set of $(m+1) *(n+1)$ points; in the case of lines the matrix row corresponds to a set of $n+1$ points. These nodes are useful for the design of trusses and frames allowing the use of Instances Nodes that link selected objects to each point of arrays. In fact "the Instance on Points node adds a reference to a geometry to each of the points present in the input geometry" (Figure 5).

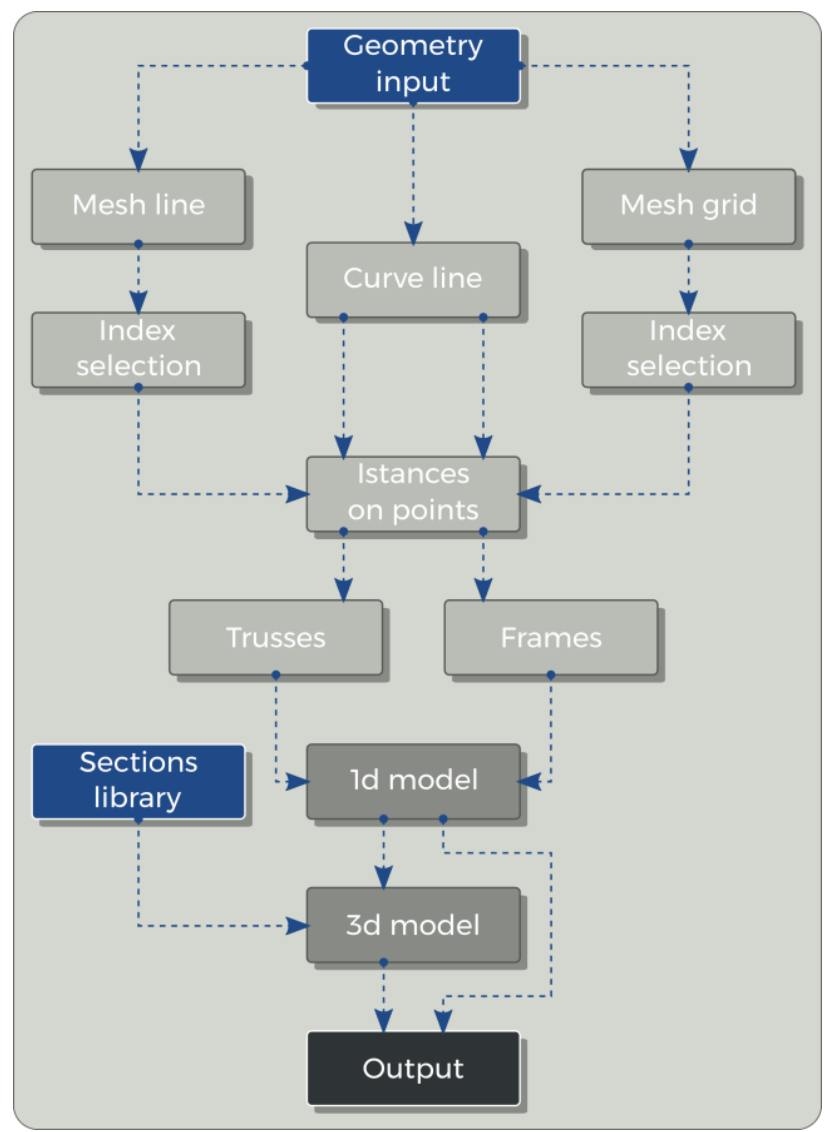

Figure 5. The VPL algorithm's architecture.

Therefore the Instances attach specific objects to the points of the Mesh Grid or Mesh Line; in the case of the modelling of tubular truss bridges, Curve Line nodes are used to generate simple lines; each of them corresponds to a member of the different macro-elements of every trellis and frame. In the case of grids, these elements are inclined and oriented along the diagonals; consequently, the lines are parametrically managed, in order to automatically adapt their geometry to the grid of points they are assigned. For the modelling of diagonal grids a crucial point has been the possibility of selecting alternately the points of the matrix characterised by even or odd indexes, both in rows and in columns. This requirement is guaranteed thanks to the opportunities offered by Fields in Blender, "a set of instructions that can transform an arbitrary number of inputs into a single output". In this case, fields for the selection tools are based on the use of index nodes that refer to the index of each point; an index is an integer number that corresponds to 0 for the first point, to $m * n-1$ to the last one. These nodes work as control parameters via a routine consisting of a series of operations similar to those accurately described by Johnny Matthews. The routine consists of comparing indexes with a combination of mathematical functions: division, floor, and modulo. modelling horizontal or vertical frames is particularly simple and fast; it consists only in instancing objects generated by Curve Line nodes to the points of Mesh Lines; however, even in this case the selection of specific points can be obtained in the same way as proposed for the grids. The model of a truss or a deck can be copied through the use of Transform Node that is managed by a vector describing the required translation for the correct placement of each object. The $1 \mathrm{~d}$ modelling can be followed by the rendering of the $3 \mathrm{~d}$ model (Figures 5,8,9).

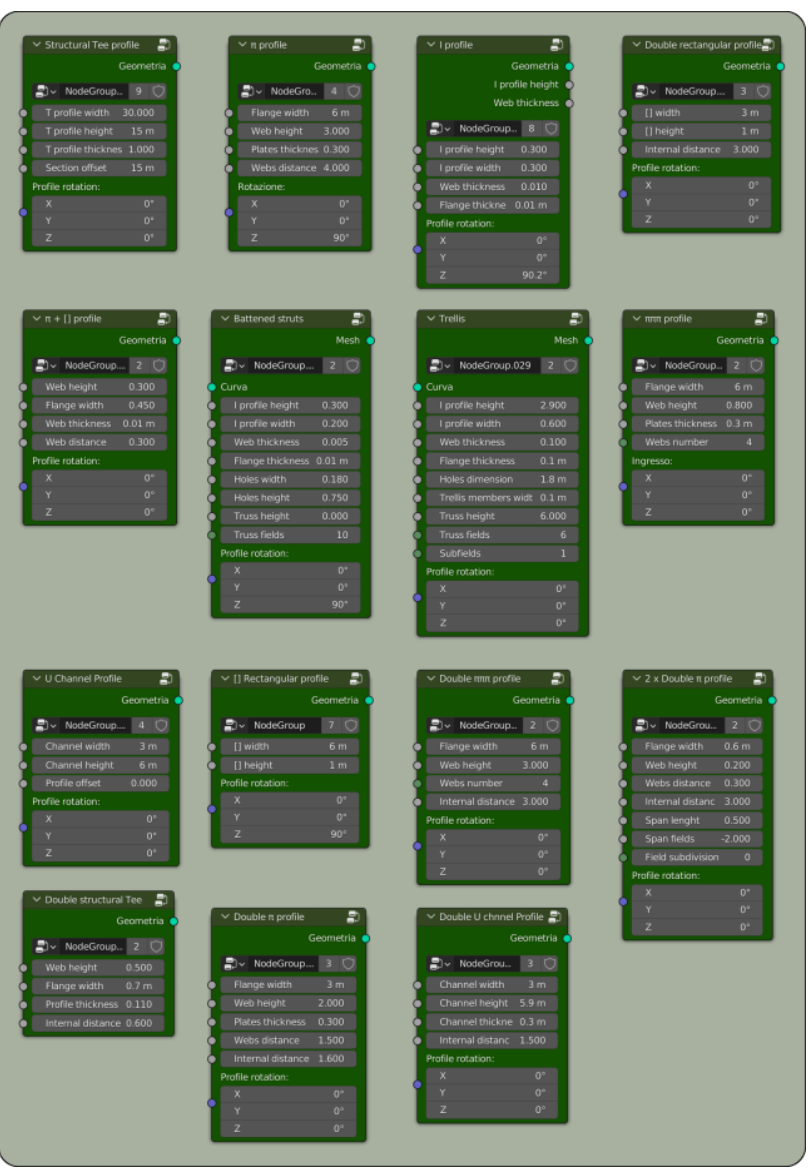

Figure 6. The sections library in Blender Geometry Nodes.

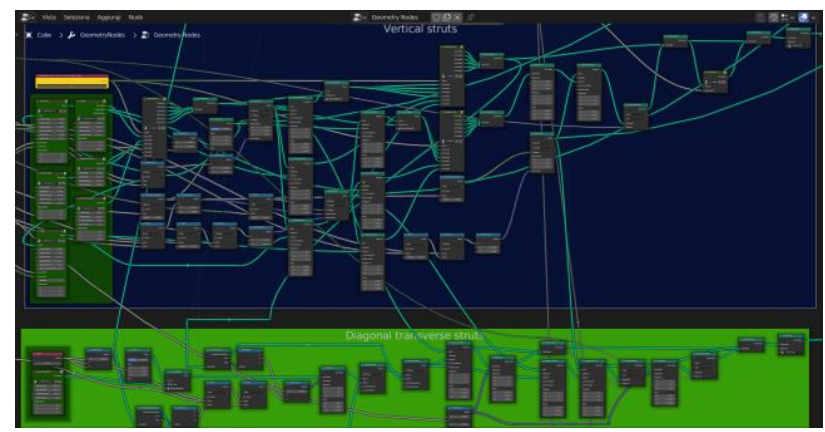

Figure 7. The grouping of Blender's Gemetry Nodes in Frames and the relative second level of input section.

However, this step requires a second input level, which follows the initial one; the first one consists of the introduction of principal dimensions of each bridge, functional to the modelling of the $1 \mathrm{~d}$ model. The second input level consists of the selection of shapes and, subsequently, of the definition of their dimensions and mutual position (Figure 7). 


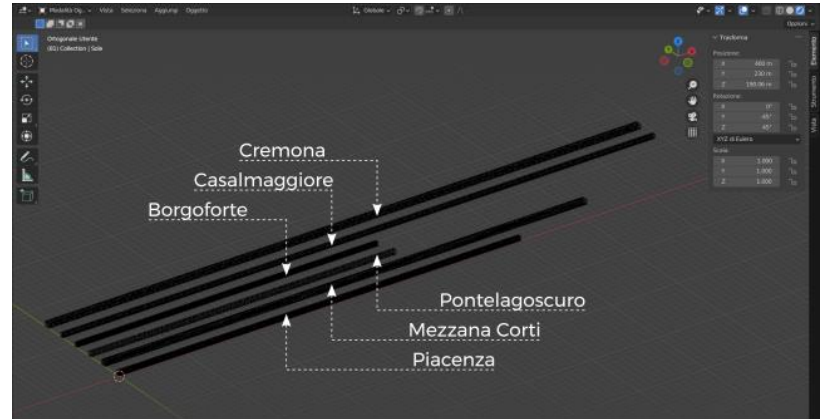

Figure 8. The 1d modelling of the six bridges over the Po.

This double input level is identified by a specific colour, green, as well as nodes for the selection of various parameters can be immediately identified by yellow. An important feature in Blender is the display of input data - those to be introduced in the main input group - in the lateral bar; this feature allows quick input and does not require to navigate inside the algorithm. Another important feature is the Frame node - a container of nodes - that allows their grouping and can be displayed with a specific colour in order to identify specific sequences of operations.

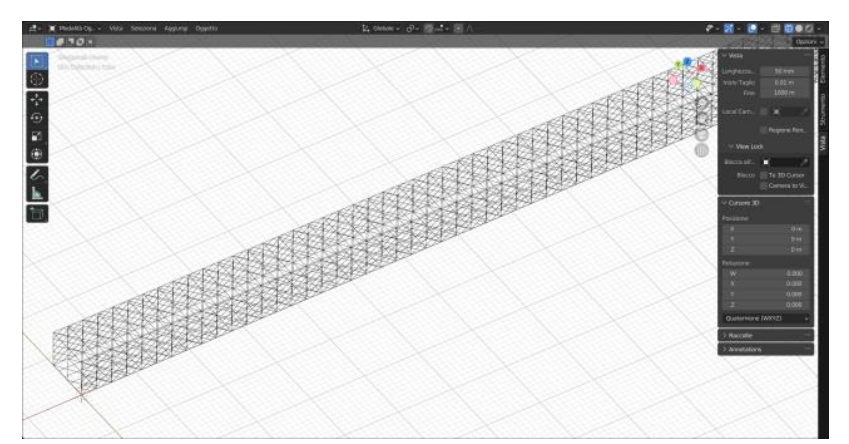

Figure 9. The 1d modelling of the bridge in Casalmaggiore.

As a consequence, a Frame has the same colour of the material assigned to members they refer to. A section dedicated to the second level input is placed inside each Frame and is always identified by the green colour; it relates to the selection of the type of shapes and their dimensions.

In addition, a useful feature of Blender's Geometry Nodes is that copies of groups generated by the VPL algorithm preserve the possibility to be parametrically modified and are independent of other copies.

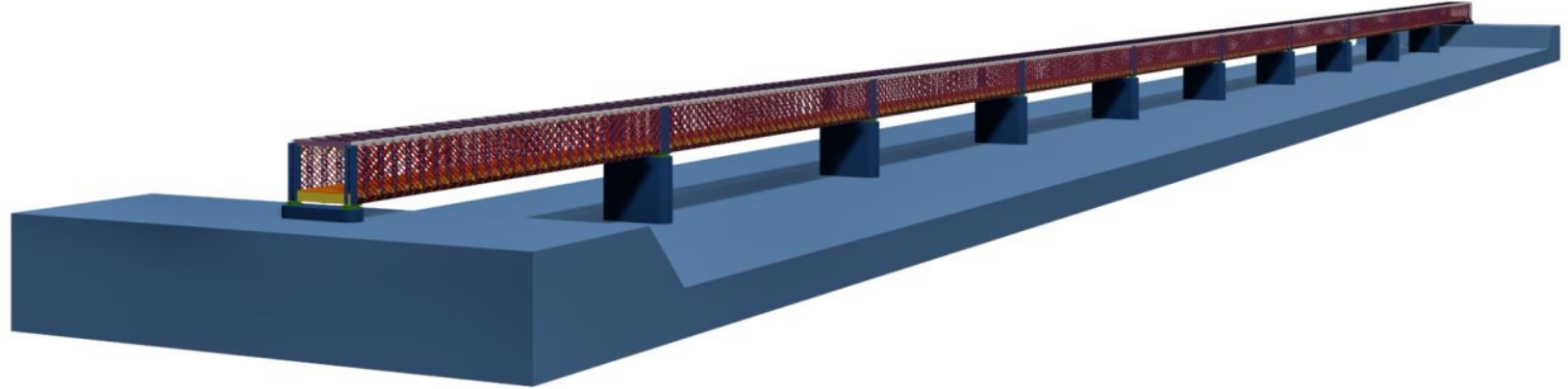

Figure 10. A general view of the bridge in Mezzana Corti

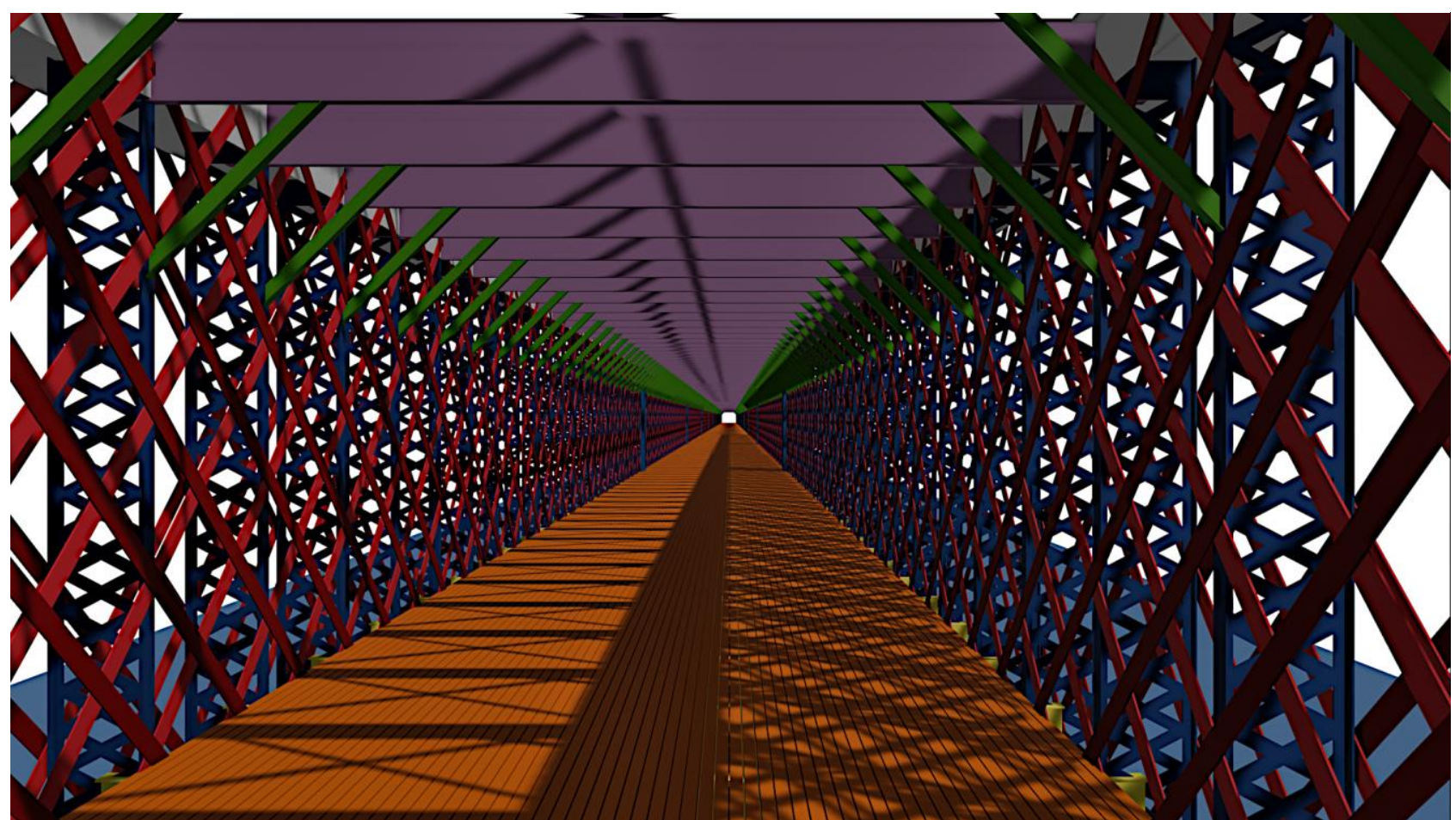

Figure 11. A view of the bridge in Mezzana Corti; vertical struts were trellis, diagonal members were juxtaposed plates, bracing were Tee sections and the floor consists of wood. 


\section{CONCLUSION}

The proposed algorithm proved to be quite flexible for the modelling of the six iron bridges over the Po. In the case of $1 \mathrm{~d}$ models, it is absolutely suitable for the drawing of all possible geometrical configurations. In the case of $3 \mathrm{~d}$ modelling, it is able to parametrically render a large part of the features highlighted by the analysis of the sources related to case studies (Figures 10-12). However, some exceptions are not yet well implemented in the algorithm's architecture, for example particular components such as lateral sidewalks or the complex drawing of diagonal transverse struts that at this stage can be only displayed in a simplified version - or lateral balustrades on the upper level.

The bridge in Cremona, which consists of two lattice tubes placed side by side, was modeled with a copy of the first bridge, simply changing the width of the copy; however, the algorithm can be revised to include specific parameters for managing the number of transverse spans. Another exception that the algorithm must include is the possibility of differentiating the length of some spans, managing two or more span lengths for each bridge.

Another aspect to explore is the conversion and the export of the 3d-model in IFC (Industry Foundation Classes) format, using a specific Add-on, the BlenderBim, even though this aspect is partly independent of the development of the algorithm itself. The IFC export guarantees a considerable level of interoperability between different BIM software, facilitating further dissemination of the algorithm.

Anyway, the outcomes reached at this stage by the algorithm's development already prefigure great potential for dissemination purposes, in order to reach the main goal of rediscovering and enhancing nineteenth-century construction techniques that were a fundamental step for the scientific and technological progress of the young Italian nation.

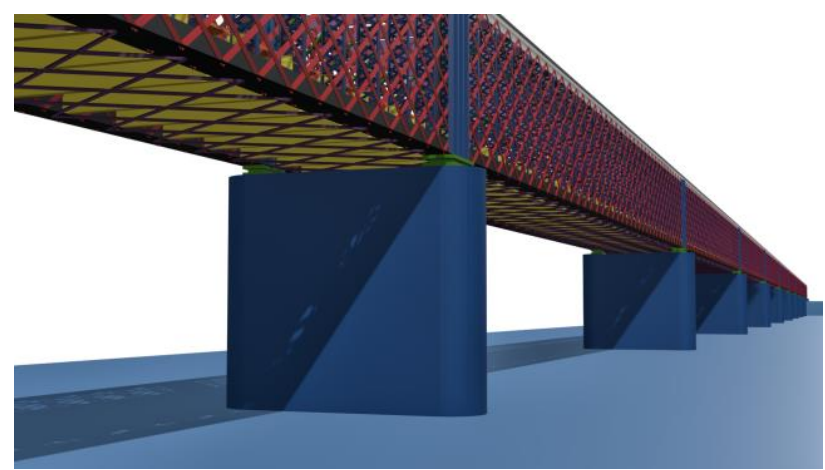

Figure 12. Bottom view of the bridge in Mezzana Corti.

\section{REFERENCES}

Andriasyan, M., Moyano, J., Nieto-Julián, J. E. and Antón, D., 2020. From point cloud data to building information modelling: An automatic parametric workflow for heritage. Remote Sensing, 12(7), 1094. https://doi.org/10.3390/rs12071094

Beduzzi, R., 1900. Il ponte sul Po a Cremona. Giornale del Genio Civile (Parte non ufficiale), 9, 81-134, 1900.

Bianchi, E., 1912. Il completamento del sovrapassaggio ed i lavori di rafforzamento al ponte sul Po presso Mezzanacorti. Rivista tecnica delle ferrovie italiane, 196-203.
Bianconi, F. and Filicci, M., 2021. Digital draw connections: Representing complexity and contradiction in landscape. Springer Nature, Berlin.

Blender (version 3.1.0 Alpha) [GPL software], 2022. https://www.blender.org/

Broglio, A., 1872. Ponte in ferro sul Po per la ferrovia BolognaPadova. Giornale del Genio Civile (Parte non ufficiale), 7 serie B, 76-89.

Brumana, R., Oreni, D., Raimondi, A., Georgopoulos, A. and Bregianni, A., 2013. From survey to HBIM for documentation, dissemination and management of built heritage: The case study of St. Maria in Scaria d'Intelvi. 2013 Digital Heritage International Congress (DigitalHeritage). http://dx.doi.org/10.1109/digitalheritage.2013.6743789.

Brusaporci, S., 2017. Digital innovations in architectural heritage conservation: Emerging research and opportunities. IGI Global, Hershey.

Brusaporci, S., Maiezza, P. and Tata, A., 2018. A framework for architectural heritage Hbim semantization and development. The Int. Arch. Photogramm. Remote Sens. Spatial Inf. Sci., XLII-2, 179-184. https://doi.org/10.5194/isprs-archives-xlii-2$179-2018$

Brusaporci S., Tata, A. and Maiezza. P., 2021. The "loh - Level of history" for an aware HBIM process. 42th International conference of representation disciplines teachers. Congress of Unione Italina per il disegno. Proceedings 2020: Linguaggi, distanz, tecnologie. FrancoAngeli, Milan. http://dx.doi.org/10. 3280/oa-693.117.

Caccialanza R., I ponti sul Po dirimpetto a Piacenza (18012013). Documenti inediti, storia, vicende, aneddoti e notizie attraverso i secoli. Edizioni Fantigrafica, Cremona.

Capurso, G., Giannetti, I., 2019. "Reconstructive re-drawings" and "reconstructive models" for history of construction. The experience of SIXXI research. TEMA, 5(1), 36-46. https://rivistatema.com/reconstructive-re-drawings-andreconstructive-models-for-history-of-construction-theexperience-of-sixxi-research/

Carughi, U. and Guida, E., 2003. Alfredo Cottrau, 1839-1898: L'architettura del ferro nell'Italia delle grandi trasformazioni. Electa, Napoli.

Croci A., 1888. Il ponte sul Po a Casalmaggiore. Giornale del Genio Civile (Parte non ufficiale), 5, 65-74, 152-217.

Diara, F. and Rinaudo, F., 2019. From reality to parametric models of cultural heritage assets for HBIM. Int. Arch. Photogramm. Remote Sens. Spatial Inf. Sci., XLII-2/W15, 413419. https://doi.org/10.5194/isprs-archives-xlii-2-w15-413-2019

Donato, V., Biagini,C., Bertini, G. and Marsugli F., 2017. Challenges and opportunties for the implementation of h-bim with regards to historical infrastructures: A case study of the Ponte Giorgini in Castiglione della Pescaia (Grosseto-Italy). Int. Arch. Photogramm. Remote Sens. Spatial Inf. Sci., XLII-5/W1, pp. 253-60.

Dore, C. and Murphy, M., 2013. Semi-automatic modelling of building façades with shape grammar using historic building 
information modelling. The Int. Arch. Photogramm. Remote Sens. Spatial Inf. Sci., XL-5/W1, 57-64. https://doi.org/10.5194/isprsarchives-xl-5-w1-57-2013

Dore, C. and Murphy, M., 2019. Historic building information modelling (HBIM). Architecture and Design. IGI Global, Hershey, 49-92. http://dx.doi.org/10.4018/978-1-5225-73142.ch003

García Valldecabres, J. L., López González, M. C. and Jordán Palomar, I., 2017. The study of architectural heritage with HBIM methodology. A medieval case study. Architectural Draughtsmanship. Springer International Publishing, Berlin, 945-955. http://dx.doi.org/10.1007/978-3-319-58856-8_74.

Giornale del Genio Civile, 1870. Ponte stabile sul Po a Pontelagoscuro per la ferrovia Bologna-Padova. Giornale del Genio Civile, (Parte non ufficiale). Cronaca delle opere pubbliche, 49, 428-429.

Iodice, R., 1985. L'architettura del ferro. L'Italia 1796-1914. Bulzoni, Roma.

Iori, T. and Poretti. S., 2015. SIXXI. Storia dell'ingegneria strutturale in Italia. Gangemi, Rome.

Iori, T., Giannetti, I. and Capurso, G., 2019. SIXXIGames: Serious games to educate young architects and structural engineers. Structures and Architecture: Bridging the Gap and Crossing Borders. CRC Press, Leiden ,468-475. http://dx.doi.org/10.1201/9781315229126-55.

Johnston, W. M., Hanna, J. R. P. and Millar, R. J., 2004 Advances in dataflow programming languages. $A C M$ Computing Surveys, 36(1), 1-34. https://doi.org/10.1145/101320 8.1013209

Murphy, M., McGovern, E. and Pavia, S., 2013. Historic Building Information Modelling - Adding intelligence to laser and image based surveys of European classical architecture. ISPRS Journal of Photogrammetry and Remote Sensing, 76, 89102. https://doi.org/10.1016/j.isprsjprs.2012.11.006

Nascè, V. (ed.), 1982. Contributi Alla Storia Della Costruzione Metallica, CTA Collegio dei Tecnici dell'Acciaio.

Oreni, D., 2013. From 3D content models to HBIM for conservation and management of built heritage. Lecture Notes in Computer Science. Springer Berlin Heidelberg, 344-357. http://dx.doi.org/10.1007/978-3-642-39649-6_25.

Pereira, Á., Cabaleiro, M., Conde, B. and Sánchez-Rodríguez, A., 2021. Automatic Identification and Geometrical modelling of Steel Rivets of Historical Structures from Lidar Data. Remote Sensing, Vol. 13., pp. 1-17.

Pozzi, L., 1915. Ponte di ferro sul Po a Piacenza, Costruzione ed esercizio delle strade ferrate e delle tramvie. Album di costruzioni ferroviarie. Unione Tipografico - Editrice Torinese, Torino.

Previtali, M., Brumana, R., Stanga, C. and Banfi, F., 2020. An ontology-based representation of vaulted system for HBIM. Aied Sciences, 10(4), 1377. https://doi.org/10.3390/a0041377.

Qin. G., Zhou, Y., Hu, K., Han, D. and Ying C., 2021. Automated Reconstruction of Parametric BIM for Bridge Based on Terrestrial Laser Scanning Data. Advances in Civil Engineering, 2021: pp. 1-17.

Ratti, G., 1874. Cenni intorno alla costruzione del ponte di ferro sul Po a Borgoforte per la ferrovia Mantova-Modena. Stab. G. Civelli, Firenze.

Ratti G., 1876. Ponte sul Po a Pontelagoscuro. Il Politecnico Giornale dell'Ingegnere Architetto Civile e Industriale, 12-26.

Ratti G., 1879. Ponte sul Po a Borgoforte. Il Politecnico Giornale dell'Ingegnere Architetto Civile e Industriale, 563585.

Repenning, A., 2017. Moving beyond syntax: Lessons from 20 years of blocks programing in agentsheets. Journal of Visual Languages and Sentient Systems, 3(1), 68-91. https://doi.org/10.18293/vlss2017-010

Sacheri, G., 1888. Il Ponte sul Po a Casalmaggiore per la ferrovia Parma-Brescia. L'Ingegneria Civile e e le Arti industriali, 129-132.

Sacheri, G., 1892. Il grande ponte sul Po presso Cremona. La Ingegneria Civile e le Arti industriali, 155-159.

Sztwiertnia, D., Ochałek, A., Tama, A. and Lewińska, P., 2019. HBIM (heritage building information modell) of the Wang Stave Church in Karpacz - case study. International Journal of Architectural Heritage, 15(5), 713-727. https://doi.org/10.1080/ 15583058.2019 .1645238

Valsecchi, P., 1868. Ponte tubolare sul Po presso Mezzanacorti ed opere relative di difesa e di nuova inalveazione. Giornale del Genio Civile (Parte non ufficiale), 30, 325-359.

Verdiani, G., Peruzzi, A. and Gualandi, M., 2014. The Piacenza Cathedral, from the digital survey to a complete multimedia documentation. Built Heritage: Monitoring Conservation Management, 313-321. Springer International Publishing, Berlin. http://dx.doi.org/10.1007/978-3-319-08533-3_26

Yang, L., Cheng, C.P. and Wang. Q., 2020. Semi-Automated Generation of Parametric BIM for Steel Structures Based on Terrestrial Laser Scanning Data. Automation in Construction, Vol. 112. doi.org/10.1016/j.autcon.2019.103037.

Zordan, M., 2006. L'architettura dell'acciaio in Italia. Gangemi, Roma.

Zorgno Trisciuoglio, A.M., 1988. La materia e il costruito. Alinea, Firenze. 